\title{
Improving Food Security in an Eco-Friendly Manner through Integrated Aquaculture
}

\author{
Olawale Ahmed Onada1, Oluniyi Solomon Ogunola² \\ ${ }^{1}$ University of Bremen, Bremen, Germany \\ ${ }^{2}$ University of Ibadan, Ibadan, Nigeria \\ Email: onadaolawale@gmail.com,solomonunilag@yahoo.com
}

Received 23 February 2016; accepted 8 March 2016; published 11 March 2016

Copyright (C) 2016 by authors and OALib.

This work is licensed under the Creative Commons Attribution International License (CC BY). http://creativecommons.org/licenses/by/4.0/

\section{(c) (i) Open Access}

\section{Abstract}

As the global population increases, demand for food, most especially protein, will increase. The increasing production from agriculture, including forestry and fisheries, has, however, contributed significantly to global food security but most often at the expense of environmental deterioration. Integrated aquaculture (IA) can guarantee and sustain adequate food security in environmentally friendly manner. Integrated fish farming is a diversified and coordinated way of farming with fish as the main target along with other farm produces. The aim of integrated fish farming is to create a mutually beneficial system that will lead to maximization of productivity through optimum resource use. The major features of this system include: multiple production that leads to increased productivity from the combination of different farming system, recycling of waste or by-product in which the waste of one system becomes the input of another system thereby reducing the amount of waste generated and input resources, efficient utilization of farm space for multiple production, provision of steady source of income all year round to the farmer; this comes from various farm products. In any integrated system, the interrelationships are many; crop byproducts are fed to animals, while fish and animal manures are returned to the crops and fish in the ponds. The fish may feed on insects and weed in the rice field planted inside the pond and this in turn can increase the available nutrients to the crop. IA has ample capacity of making more food available thus enhancing food security. Aside from production enhancement, integrated fish farming also gives a platform for managing environmental integrity through waste recycling and utilization. It is important therefore to encourage farmers and other food production sectors to engage in a production system that will ensure food security in an eco-friendly manner.

\section{Keywords}

Fish Production, Agriculture-Aquaculture System, Eco-Friendly Aquaculture

Subject Areas: Aquaculture, Fisheries \& Fish Science 


\section{Introduction}

As the global population increases, demand for food, most especially protein, will increase. Production from agriculture, including forestry and fisheries, is crucial for food security in the face of current population increase. In order to secure global food security, it is imperative that more food needs to be produced so as to strike balance between increasing human population and food availability. In this regard, sustenance of increased productivity must emphasize on the development of strategies aimed at improving yield through rational utilization of resources and proper environmental management, such as strategies abound in integrated aquaculture (IA). Integration aquaculture with crop production and animal husbandry is one of the indubitable ways to increase the level of food production and simultaneously maintain equitable use of available land and human resources to meet human food demands in an environmentally sustainable manner. This is because integrated aquaculture productivity has been confirmed to relatively reduce cost of production [1] and thus the sustenance of increased food production must increase farmers' income, nutrition and also entrench the development of strategies aimed at overall welfare [2]. In order to encourage food security of human population, there is the need for farmers to engage in a result oriented farming system that can guarantee and sustain adequate food security in environmentally friendly manner. This review emphasizes the food security improvement contribution of integrated aquaculture in an environmentally friendly manner.

\section{Rationale of Integrated Aquaculture (IA)}

Integrated aquaculture is a method of farming which is generally believed to help the rural poor to utilize resources at their disposal towards maximizing production and making more profit from their investment. IA reduces waste generated from different sub-systems on the farm and also increases water use efficiency through the utilization of waste in one sub-system as resource or input in another sub-system within a system of production, recycling and re-use of water in one sub-system for irrigation in another sub-system. This will, however, reduce the negative impact of farming on the environment due to zero tolerance to waste discharge to the environment while at the same time improve economy of production for profit maximization of the farmers.

\section{Forms and Feasibility of Integrated Aquaculture}

Integration of animal rearing, crop production with fish farming is the most complex of all forms of integrated aquaculture and consists of raising animal and plants on or near fish ponds. Each component of the system receives something and gives something to other components. The feasibility of this system has been earlier carried out in NIFFR (National Institute for Freshwater Fisheries Research) by [3] where he found that integrated combination of fish with poultry and crop is feasible with better performance as compared with single production of the individual systems. The research on the integration of animal and fish by [4] divides the system of production under integrated aquaculture into two:

> Semi-integration (raising livestock on land and transporting the manure to the fish pond, using waste water from pond to irrigate crop outside the perimeter of the pond).

$>$ Complete or Vertical integration (raising livestock directly above the fish pond so that animal manure can drop directly into the fish pond, growing vegetable on the dyke or center of the pond where it can easily utilize the pond water).

Conventionally, IA combines animal husbandry and crop production either singly or in combination with fish production in a strategic way that can ensure mutual interrelationship. IA can come in the form of crop-fish-livestock integration, livestock-fish integration, crop-fish integration and crop-livestock-agro-processing integration.

\section{Benefits of Integrated Aquaculture}

The benefits of integrated Aquaculture system are enormous and encompass those of traditional farming system and modern farming system. The benefits of IA include the following.

\subsection{Food Security}

IA improves food security due to its various combinations of crop, livestock and fish. More food is thus produced in the single production from the various combinations. 


\subsection{Self Sufficiency}

IA is suitable for low income farmers with remarkably low expenditure pattern and continuous low spending for food and other dietary requirement. The system is all encompassing as the time is well utilized in other farming activities depending on the type of integration involved. In fish cum crop production, crops like the vegetables are harvested continuously even in dry season as water from the pond is used to water the farms adequately.

\subsection{Production Indices}

Field studies show that variable and fixed inputs are well utilized in integrated aquaculture as compared with single system of production as presented in Table 1.

\subsection{Regular Source of Income}

IA provides platform for steady source of income all year round; this comes from various farm products. For example, in poultry, vegetable cum fish farming, before the harvesting of the fish, which may take some months, the farmer can sell the eggs and vegetables which will generate money for some time.

Table 1. Production indices.

\begin{tabular}{|c|c|c|c|c|c|c|c|c|}
\hline \multirow[b]{2}{*}{ Fixed input } & \multicolumn{4}{|c|}{ Integrated Fish Farming } & \multicolumn{4}{|c|}{ Single Production System } \\
\hline & Pig & Poultry & Rice & Fish & Pig & Poultry & Rice & Fish \\
\hline Land & $\mathrm{R}^{*}$ & $\mathrm{R}^{*}$ & $\mathrm{R}^{*}$ & $\mathrm{R}^{*}$ & $\mathrm{R}$ & $\mathrm{R}$ & $\mathrm{R}$ & $\mathrm{R}$ \\
\hline Cage & - & $\mathrm{R}$ & - & - & - & $\mathrm{R}$ & - & - \\
\hline Poultry house & - & $\mathrm{R}$ & - & - & - & $\mathrm{R}$ & - & - \\
\hline Pig sty & $\mathrm{R}$ & - & - & - & $\mathrm{R}$ & - & - & - \\
\hline Fish pond & - & - & - & $\mathrm{R}$ & - & - & - & $\mathrm{R}$ \\
\hline \multicolumn{9}{|l|}{ Variable input } \\
\hline Fish seed & - & - & - & $\mathrm{R}$ & - & - & - & $\mathrm{R}$ \\
\hline Poultry feed & - & $\mathrm{R}^{*}$ & - & - & - & $\mathrm{R}$ & - & - \\
\hline Fish feed & - & - & - & $\mathrm{R}^{*}$ & - & - & - & $\mathrm{R}$ \\
\hline Pig feed & $\mathrm{R}^{*}$ & - & - & - & $\mathrm{R}$ & - & - & - \\
\hline Rice seed & - & - & $\mathrm{R}$ & - & - & - & $\mathrm{R}$ & - \\
\hline Rice processing & - & - & $\mathrm{R}$ & - & - & - & $\mathrm{R}$ & - \\
\hline Irrigation services & - & - & - & - & - & - & $\mathrm{R}$ & - \\
\hline Organic manure & - & - & $\mathrm{R}$ & $\mathrm{R}$ & - & - & $\mathrm{OP}$ & OP \\
\hline Inorganic fertilizer & - & - & - & - & - & - & $\mathrm{R}$ & $\mathrm{OP}$ \\
\hline Labour & $\mathrm{R}^{*}$ & $\mathrm{R}^{*}$ & $\mathrm{R}^{*}$ & $\mathrm{R}^{*}$ & $\mathrm{R}$ & $\mathrm{R}$ & $\mathrm{R}$ & $\mathrm{R}$ \\
\hline Health services & $\mathrm{R}$ & $\mathrm{R}$ & - & $\mathrm{R}$ & $\mathrm{R}$ & $\mathrm{R}$ & - & $\mathrm{R}$ \\
\hline
\end{tabular}

$\mathrm{R}^{*}=$ required in a reduced quantity or cost; $\mathrm{R}=$ required; $\mathrm{OP}=$ optional. 


\subsection{Waste Recycling}

The waste products of one biological system serve as input for other biological system. For example, in the integration of fish and poultry, the droppings from poultry can be used to fertilize fish pond and also serves as maggot generation medium which serves as input to the fish production system, also, when the fish are harvested, the fish offal can be dried and used for poultry feed. The common feature of most integrated aquaculture systems is that livestock excreta are used as fertilizer for crop production; and livestock waste is also used to enhance the growth of various natural planktons in the ponds which may serve as fish feed.

\section{Water Use Efficiency and Productivity in IA}

The importance of water in agriculture production cannot be over-emphasized. In production from agriculture, including fish production, water is gotten majorly from precipitation, underground water and reservoirs including rivers and lakes. However, water supply from these sources is not entirely reliable. The growing world population requires increased food production, while available water resources may not be sufficient for agriculture. This alarming situation can only be resolved if water is managed more efficiently, so that yield of agriculture produce per unit of water consumption increases. To increase agriculture per water usage, a system that will ensure recycle and re-use of water will need to be entrenched. Such system is obtainable in IA. IA will assure high water productivity in agricultural production system. Water productivity is defined as the ratio of the net benefits from crop, forestry, fishery, livestock, and mixed agricultural systems to the amount of water required to produce those benefits. In its broadest sense it reflects the objectives of producing more food, income, livelihoods, and ecological benefits at less social and environmental cost per unit of water used, where water use means either water delivered to a use or depleted by a use. Put simply, it means growing more food or gaining more benefits with less water. In fish-crop integration, the waste water from aquaculture can be used to irrigate crop production thereby increasing the use to which the water is employed. In this case, water serves dual purpose of usage in fish production and crop irrigation, and also maintained increase productivity of agriculture produce.

\section{Ecological Significance of Integrated Fish Farming}

Sustainable aquaculture depends upon eco-friendly culture system for its survival. One of the interesting features of IA is that it leads us to view systems under integration as synergistic components. IA are comprised of different ecosystems that can be described, modeled, analyzed and compared; they are guided by principles, and the parts that make them up and the way these parts are related [5].

In any integrated system, the interrelationships are many; crop byproducts are fed to animals, while fish and animal manures are returned to the crops and fish in the ponds. The fish may feed on insects and weeds in the rice field planted around the pond, and when the pond water is used to irrigate the crop, this in turn will increase the available nutrients to the crop. The ecological efficiency of an integrated fish farm is very paramount to the success of the entire farming enterprise. The synergistic and mutually beneficial approach of IA is what makes it different from several other systems of agriculture production.

\section{Importance of Nutrient Cycling in IA}

Nutrient recycling in IA provides the opportunity of managing organic waste to an extent that close to zero tolerance is given to waste discharge to the environment; also, the concept of turning waste to resources will bring about increase productivity and provide huge economic benefits. This is important to sustainable aquaculture, and reduces expenses on feed and fertilizer to a large extent. Outside the possibility of sustainable aquaculture production, environmental sustainability is also one of the importances of IA. It is however important to be able to determine and quantify nutrient flow in such a way that will strike balance between demand and supply of bio-resources in and out of a system. For effective cycling of nutrients in IA, a balance of bio-resources must be established within each system, strict ecosystem monitoring and management must be ensured, taking into cognizance the type and level of integration involved.

In time immemorial, poultry droppings have been used as fertilizer in fish pond to encourage the growth of phytoplankton and zooplanktons, and also to supply undigested feed in the dropping for consumption of fish, this poultry dropping also act as organic fertilizer to planted crop when applied directly. Recently, nutrient rich 
pond water has also been used for irrigation of crops most especially vegetables and rice.

\section{Ecological Sustainability of Integrated Aquaculture}

All modern, large scale food systems have discernible environmental and social impacts. Even the sustainability of modern, large scale, organic agriculture has been questioned. The sustainability of ecological parameters in any agro-ecosystem is very important in determining the success of the farming venture. The Broundtland Commission [6] defined sustainable development as the ability to meet the needs of the present without compromising the ability of the future generation to meet their own needs. Some forms of integrated aquaculture development have caused severe social and environmental impacts [7]. The degraded state of most aquatic ecosystems combined with public concerns about adding "new" sources of aquatic pollution to the already overburdened ecosystems will require aquaculture to develop new ecosystem approach and sustainable operating procedures [8]. Poorly managed integrated systems usually have high nutrient loading leading to deleterious effect of cyanobacterial bloom [9], reverse is the case if the system is well managed. In a well-managed system, there is relatively low to zero output of waste. However, ecologically sustainable aquaculture is the development of aquatic farming systems that preserve and enhance the forms and functions of the natural and social environments in which they are situated. It involves realistic ecological approaches that will develop aquaculture production techniques for various integration systems, by using local resources, effective recycling of wastes and materials that can degrade natural ecosystems and proper planning for job creation and marketing strategies that will be widely accepted as meeting both economic and ecological considerations [10].

\section{Comparison of Productivity on Integrated Aquaculture and Conventional System}

The productivity of integrated aquaculture as compared with conventional system of production of agricultural produce has been compared by [11] as presented in Table 2 . The advantage of integrated aquaculture is revealed in the research which showed increased productivity.

\section{Constraint of Integrated Fish Farming}

As it has been observed through several field practices, poly-culture of Tilapia and catfish integrated in a rice paddy area is inefficient in productivity, this is because tilapia has the capacity to destroy rice bed by digging the rice bed to prepare nest for reproduction, thereby reducing the space available for rice production. Synergistic characteristics of IA needs to be properly understood before combination, this is because through waste recycling, the waste from one system that should serve as input in the other can end up becoming a threat, for example, poultry dropping that should fertilize a pond can become a threat to the fish if over-fertilized. Link in different sub-systems needs to be adequately quantified so that resources can be allocated in the right quantity and proportion.

\section{Conclusion and Recommendation}

IA has ample capacity of making more food available thus enhancing food security. Aside from production en-

Table 2. Summary of comparative performance of fish, rice and poultry production of integrated system and conventional system in terms of growth, yield and egg production.

\begin{tabular}{|c|c|c|c|c|c|c|c|c|}
\hline & \multicolumn{2}{|c|}{ Fish } & & \multicolumn{2}{|c|}{ Rice } & & \multicolumn{2}{|c|}{ Pig } \\
\hline & CS & IS & & CS & IS & & CS & IS \\
\hline IFW (g) & 42 & 10 & $\mathrm{RS} / 60 \mathrm{~m}^{2}$ & 1200 & 1000 & IW & 15.26 & 14.1 \\
\hline Av feed/fish & 639 & 221 & yield $(\mathrm{kg}) / 60 \mathrm{~m}^{2}$ & 12.67 & 23 & FW & 41.24 & 41.8 \\
\hline AWG & 395 & 179 & yield (ton/hec) & 2.08 & 3.8 & WG & 26.0 & 27.7 \\
\hline FCR & 1.7 & 1.25 & & & & & 4.2 & 3.6 \\
\hline
\end{tabular}

IFW = Initial fish weight; RS = Rice stand; IW = Initial weight; AWG = Average weight gain; FCR = Feed conversion ratio; CS = Conventional system; IS = Integrated system; FW = Final weight; $\mathrm{WG}=$ Weight gain. 
hancement, integrated fish farming also gives a platform for managing environmental integrity through waste recycling and utilization. It is important therefore to encourage farmers and other food production sectors to engage in a production system that will ensure food security in an eco-friendly manner.

\section{References}

[1] Ugwumba, C.O.A. and Orji, E.C. (2006) Traditional Farming System and Its Effect on Farm Cash Income in Old Njikoka Local Government Area of Anambra State. Int. J. Agric. Res. Politics, 1, 21-24.

[2] Okoye, F.C. (2004) Integrated Rice-Fish Farming in Nigeria: Its Feasibility and Economic Viability. 18th Annual Conference of the Fisheries Society of Nigeria (FISON), Owerri, 8-12 December 2003, 168-172. http://aquaticcommons.org/872/1/FISON2003 168\%2D172.pdf

[3] Otubusin, S.O. (1986) Modern Aquaculture Practices for Increased Fish Production in Nigeria. 3rd Annual Conference of the Fisheries Society of Nigeria (FISON), Maiduguri, 22-25 February 1983, 89-104.

[4] Barash, H., Planik, I. and Moar, R. (1982) Integration of Duck and Fish Farming: Experimental Results. Agriculture, 27, 129-140.

[5] Altieri, M.A. (1987) Agro Ecology the Scientific Basis of Alternative Agriculture. Intermediate Publications, London, 45-48.

[6] WCED (World Commission on Environmental and Development) (1987) Environment Our Common Future. Oxford University Press, Oxford, 1-4.

[7] Black, K.D. (2000) Environmental Impacts of Aquaculture. CRC Press, Boca Raton, 36.

[8] Akpan, E.R. and Okafor, N. (1997) On Organic Fertilization and Plankton Development in Two Experimental Fresh Water Ponds of Nigeria. J. Aqua. Trop, 12, 147-154.

[9] Pearl, H.W. and Tucker, O.S. (1995) Ecology of Blue-Green Algae in Aquaculture Ponds. Journal of the World Aquaculture Society, 26, 109-131. http://dx.doi.org/10.1111/j.1749-7345.1995.tb00235.x

[10] Costa Pierce, B.A. (2002) Farming Research and Extension Methods for the Development of Sustainable Aquaculture Ecosystems. In: Costa Pierce, B.A., Ed., Ecological Aquaculture, CRC Press, Boca Raton, 103-123. http://dx.doi.org/10.1002/9780470995051.ch5

[11] Onada (2014) A Research Dissertation for the Fulfillment of Master Degree in the Department of Aquaculture and Fisheries Management. University of Ibadan, Ibadan. 